\title{
The Quest for an Ideal Mental Health Act
}

\author{
Narayan,C.L.' Jaiswal' Rajeev
}

\begin{abstract}
:
Legislation in the field of mental health is required to protect human rights of the patients, and to provide for legislative procedures for admission into mental health facilities. After a long and protracted course, the Mental Health Act (MHA) - 1987 was enacted by the Government of India (GOI). Though it contained many progressive features of advancement over the previous India Lunacy Act (ILA) - 1912, it failed to come up to expectation due to various inherent drawbacks and other factors. After ratification of the UNCRPD by India, it became imperative to amend the existing MHA - 1987. The drafting team, which has been assigned duty to prepare the new and amended proposal of the MHA by the Ministry of Health \& FW, GOI, issued a draft of a new Act, the Mental Health Care Act on 06.12.10. This proposed draft gives special stress to human rights of persons with mental illness, and makes it obligatory for the government to establish a mental health care delivery system which can be accessed by all. It also proposes to establish Mental Health Review Commission (MHRC) to review admissions to mental health facilities and to ensure human rights of persons of mental illness and State Mental Health Authority (SMHA) to perform various functions like registration and supervision of mental health facilities and other functions related to mental health services. All stake holders are being consulted in the process. But the professionals have reservations on some of its provisions. Stands of the professionals in mental health and those of the human right activists are frequently at variance with each other. Activist groups are pressing for stiff control on psychiatric institutions and practically a ban on involuntary admissions to mental health facilities. Suggestions for improvement in the proposed draft are given.
\end{abstract}

Key words - Mental Health Act, Persons with Mental Illness, Mental Health Facilities, MHRC, SMHA,

\section{INTRODUCTION:}

At the time of independence, the Indian Lunacy Act (ILA) -1912 was in force in India which was concerned mainly with custodial care aspect. After the Second World War, campaigns to recognize and uphold rights of all groups of persons gained momentum all over the World and the Universal Declaration of Human Rights was adopted by the UN General Assembly in 1948. Need was felt to make appropriate changes in the ILA - 1912 and the Indian Psychiatric Society was quick to take a lead and submitted a draft Mental Health Bill in 1950. But the government initiated the process for enactment only in 1978 and the Mental Health Bill was introduced in the Lok Sabha. It was then referred to a Joint Parliamentary Committee. After a long and protracted course Mental Health Act (MHA) was finally enacted in 1987 and thereafter after framing of the Mental Health Rules in 1990, it was finally notified to come into force in all the States and Union Territories only on April 1, 1993. But because of a large number of very complicated procedures, defects and absurdities in the Act and also in the Rules, it can never be implemented properly (Dutt, 2001). UN Convention on
Right of People with Disability (UNCRPD) was adopted in December 2006. At its foundation are the inherent dignity and the equal and inalienable rights of all people. After India ratified the UNCRPD, revision of the MHA 1987 to bring it in consonance with the UNCRPD became obligatory for the government. Advent of large number of newer psychotropic drugs and rapid advancement of Psychiatry especially Private Psychiatry changed the whole scenario of Mental Health in India. All these factors have rendered the MHA-1987 archaic and ineffective in fulfilling the current needs. Therefore, it has become necessary to make necessary amendment in the MHA 1987.

\section{The Need of an MHA}

The question arises, do we really need an MHA or can its need be dispensed with? It is pertinent to note here that not all countries in the World have an MHA, which is clear from the list below (WHO report, 2001) 


$\begin{array}{lll}\text { Region } & \text { With MH legislation } & \text { Without MH legislation } \\ \text { Africa } & 59 \% & 41 \% \\ \text { The Americas } & 73 \% & 27 \% \\ \text { Eastern Mediterranean } & 59 \% & 41 \% \\ \text { Europe } & 96 \% & 4 \% \\ \text { South-EastAsia } & 67 \% & 33 \% \\ \text { Western Pacific } & 72 \% & 28 \%\end{array}$

In absence of MH law, actions taken in respect of mental health can still be judged by common and natural law principle, i.e. the 'good faith' and 'best interest' principle. Moreover, we have the section 89 of the Indian Penal Code, which says, "Nothing which is done in good faith for the benefit of a person under twelve years of age, or of unsound mind, by or by consent, either express or implied, of the guardian or other person having lawful charge of that person, is an offence by reason of any harm which it may cause, or be intended by the doer to cause or be known by the doer to be likely to cause to that person".

But the issues relating to mental health are so complex that it is difficult to address them by the simple principle of 'good faith' and 'best interest'. Issues involved in mental health for which the legislation is required are as follows -

- To regulate and to provide for legislative requirement in respect to admission to mental health facilities, as it may involve curtailment of personal liberty of persons with mental illness. Any procedure, which involves curtailment of personal liberty in any manner whatsoever, is subject to the Article 21 of Indian Constitution, which states that "No person shall be deprived of his life or personal liberty except according to procedure established law". In 1978, the Supreme Court ruled that "The word 'law' in the expression 'procedure established by law' in Article 21 has been interpreted to mean that the law must be right, just and fair, and not arbitrary, fanciful and oppressive". .

- To protect the rights of persons with mental illness when they receive health care for their mental illness.

- To protect human rights of persons with mental illness who are exposed to a wide range of human rights violations. Promotion, protection and equal enjoyment of all human rights and fundamental freedoms are required as per the UNCRPD.
- To provide for regulatory mechanism to maintain minimum standard in mental health facilities.

- To protect persons with mental illness from medically dangerous and unsanctioned treatment or institutionalization without sufficient reasons.

- To ensure availability of psychiatric health care delivery to everyone in the community.

- To ensure treatment of persons with mental illness in the community itself as far as possible. With the advancement in psychopharmacology and growth of private sector psychiatry the scenario of psychiatric practice has changed drastically. Now most of the illnesses can be managed in the community itself. Ï\% To provide for management of estates of persons with mental illness. The existing laws presume a lack of capacity in persons with mental illness to manage their estates. But, the UNCRPD recognizes that persons with disabilities have the capacity to act, but acknowledges at the same time that they may require support to exercise this capacity.

\section{UNITED NATIONS CONVENTIONS FOR RIGHTS OF PEOPLE WITH DISABILITIES (UNCRPD)}

UNCRPD was adopted in December 2006 and India ratified it in September, 2007. The CRPD came into force so far as our country is concerned, in May 2008, after approval of the Parliament. In fulfillment of their obligations under the UNCRPD, State parties are required to bring their laws and policies in harmony with the Convention. The purpose of the UNCRPD is to promote, protect and ensure full and equal enjoyment of all human rights and fundamental freedoms by all persons with disabilities and to promote respect for their inherent dignity. It covers a number of key areas such as accessibility, personal mobility, health, education, employment, habilitation and rehabilitation, participation in political life, equality and nondiscrimination. The convention marks a shift in thinking about disability from a social welfare concern to a human rights issue, which acknowledges that societal barriers and prejudices are themselves disabling. The part of the UNCRPD is Article 12, which is concerned with the legal capacity of persons with disabilities. The clauses $2,3 \& 4$ of the article are reproduced below.

2. States Parties shall recognize that persons with disabilities enjoy legal capacity on an equal basis with others in all aspects of life. 
3. States Parties shall take appropriate measures to provide access by persons with disabilities to the support they may require in exercising their legal capacity.

4. States Parties shall ensure that all measures that relate to the exercise of legal capacity provide for appropriate and effective safeguards to prevent abuse in accordance with international human rights law. Such safeguards shall ensure that measures relating to the exercise of legal capacity respect the rights, will and preferences of the person, are free of conflict of interest and undue influence, are proportional and tailored to the person's circumstances, apply for the shortest time possible and are subject to regular review by a competent, independent and impartial authority or judicial body. The safeguards shall be proportional to the degree to which such measures affect the person's rights and interests

Clause 2 recognizes that persons with disabilities shall enjoy legal capacity on an equal basis. But it is evident from clause 3 that there may be occasions when persons with disabilities may be in need of 'support' to exercise their legal capacity. Clause 4 provides safeguard to persons with disabilities to prevent abuse of the 'support' which the persons with disabilities may require. It also specifies that the measures relating to exercise of legal capacity shall apply shortest possible time and shall be subject regular review by a competent, independent and impartial authority or judicial body.

\section{CRITICISM OF THE MHA- 1987}

The MHA - 1987 has many positive features of advancement over the ILA - 1912, like definition of mental illness in a positive way, simplification of admission and discharge process, provision of OPD services in all psychiatric hospitals, efforts to safeguard human rights of mentally ill persons etc. But it has been subject to criticism right from its enactment in 1987. It is alleged to be concerned mainly with the legal procedure of licensing mental hospitals, regulating admission in these hospitals and guardianship matters of the persons with mental illness. Other issues like mental health care delivery system or human right aspects are not properly addressed by this Act. Cumbersome licensing process, inspection by visitors and other inspecting officers, control by judicial officers etc have discouraged the establishment of private psychiatric hospital services. Nonprofessionals had the access to the confidential records of the patients in the name of inspection. Licensing of mental hospitals is presumably for the purpose of ensuring quality of services in these hospitals. Licensing however is also a major dampener for the establishment of services. There is a great paucity of services for persons living with mental illness, be they services for care and treatment, leisure and recreation, habilitation and rehabilitation. The rigorous registration requirements further discourage people from setting up services. The question of abuse comes into play only if services are in existence. A legal procedure which discourages people from entering the mental health arena and thereby further disadvantages persons living with mental illness requires reconsideration (Dhanda, 2010). General Hospital Psychiatry Units (GHPU) in Private Sector are required to be registered under the Act, while those in government sector are exempted. As a result, private general hospitals are discouraged to establish psychiatry indoor units. Assigning the role to judiciary in determining presence or absence of mental illness has been criticized by the psychiatric community. Dutta (1995) feels that having some role for the judiciary in admission and discharge of psychiatric patients is giving these things a criminal flavor. Admission process in any mental hospitals requires certification by a gazetted medical officer, which puts any private mental hospital to a disadvantage. Nonprofessionals have got the power to review the treatment records of persons with mental illness in MHA1987. A serious shortcoming of the Mental Health Act is the exclusion of Government Mental Hospitals from the scrutiny of Mental Health Authorities (Antony, 2000). Exclusion of mental retardation from the definition of mental illness has been criticized by many psychiatrists. By this exclusion criterion the MHA - 1987 has put an explicit bar on the treatment of all mentally retarded persons, including the profoundly retarded, in psychiatric hospitals. Persons who have profound mental retardation are after all, in a more pitiable condition than worst victims of most mental illnesses are. They need care in total care institutions where a psychiatrist's expertise is available, along with all other standard facilities of a psychiatric hospital (Antony, 2000).

The MHA - 1987 is the target of criticism by the human right activists also, as it involves curtailment ofpersonal liberty without the provision of proper review by any judicial body. It was stated that "the Mental HealthAct is a statute which provides a procedure by which persons living with mental illness can be denied their liberty". The Constitutional validity itself of the MHA-1987 has been questioned by human right activists. Some of thesegrounds could be the statute allows for a person living with mental illness to be institutionalized for a lifetime. They argue that though It is true that this unlimited institutionalization has to be ordered 
by a judicial authority, it is technically possible to obtain entry without judicial intervention and then keep renewing the original order if the family or friends of the person living with mental illness are of the opinion that such institutionalization is in the best interest of the person living with mental illness (Dhanda, 2010).

After the UNCRPD came into force, it became imperative for the government to revise the MHA- 1987 to bring it into consonance with the CRPD. The CRPD recognizes the right to life, liberty and integrity of all persons with disabilities, whereas the MHA - 1987 does not properly addresses the issue of rights. Moreover, the CRPD recognizes that persons with disabilities shall enjoy capacity on equal basis, though at times they may need support to exercise this capacity. The support has to be for shortest possible time, with adequate mechanism of review. However, the fact that they need to access support to exercise this capacity cannot be a basis for declaring them incompetent and appointing someone else in substitution. So, the law has to be amended to provide the support and keep the person with disabilities in control of his or her life.

\section{CURRENT PROCESS OF AMENDMENT INITIATED BYTHE GOVERNMENT}

Considering the pressing need for amendment of the MHA - 87, a National Consultation on the Mental Health Programme and on the Mental Health Act was held in January 2010 with the objective to review and identify gaps in the Mental Health Programme and actions to fill up these gaps. It was felt that the MHA 1987 needs amendments. It should move towards supporting, promoting and protecting the rights of persons with mental illness. Centre for Mental Health Law \& Policy, ILS College, Pune was given the responsibility of preparing the draft of the proposed legislation and present it to the Ministry of Health and Family welfare after having nationwide consultation on it. The first draft was circulated on 28-02-10 and after seeking objections and suggestions on the draft, a revised draft was released on 23-05-10. Based on inputs from 5 regional consultations and those provided by professional bodies and other stakeholders, third draft of amendments was released. The third draft was draft of a new Act, Mental Health Care Act, as multiple repealed sections resulted in difficulty in reading the amended Act. After having extensive national consultation on the matter, the final modified draft has been forwarded to the Ministry of Health to be put before the cabinet. The draft which in consideration of the ministry is has not been put in the public domain. Main features of the proposed third draft are as follows.

\section{MAIN FEATURES of the PROPOSED MENTAL} HEALTH CARE ACT

1. Nomenclature of the Act - The proposed Act is now Mental Health Care Act, concerned purely with health care aspects of persons with mental illness. Management of property aspect has been omitted in this draft. Supposedly this aspect is now going to be covered by an amended National Trust Act. Provision of Special Personal Representatives made in 1st and 2nd draft has been omitted in this proposed Act.

2. Persons with Mental Illness - The nomenclature 'mentally ill persons' in MHA- 87 has been changed to 'persons with mental illness'. It is stated that language has a role in stigma associated with any condition. Hence 'persons with mental illness' is the preferred term.

3. Statement of objects and reasons -The Act is stated to protect and promote the rights of persons with mental illness. It is also stated to ensure health care, treatment, and rehabilitation provided in least restrictive environment which does not intrude into their rights and dignity. It is aimed as well at improving their capacity to develop their full potential and facilitate their integration into community life. The object to 'protect society from the presence of mentally ill persons who have become or might become a danger or nuisance to others' of MHA-1987 has been dropped.

4. Mental Health Facility - Psychiatric hospitals and Psychiatric Nursing homes have been described as 'Mental Health Facility'. It is defined to include all facilities either wholly or partly meant for the care of the persons with mental illness, where persons with mental illness are admitted or reside at for care, treatment, convalescence and/or rehabilitation, either temporarily or otherwise and includes general hospital or general nursing home established or maintained by the Government or any other person, and excludes a family residential place if a person with mental illness resides with his or her own family. It is obvious that psychiatric OPD services are not covered by this definition.

5. Mental Health Professionals - A new category of 'Mental Health Professional' has been created which includes psychiatrist, clinical psychologist, psychiatric social worker and registered mental health nurse with degree in psychiatric nursing. This category is created to facilitate involuntary admissions under section 45 of 
the Act. They can also become professional members in Mental Health Review Commission (MHRC) as well as in State Mental Health Authority.

6. Mental IIlness - It has been defined as a disorder of mood, thought, perception, orientation or memory which causes significant distress to a person or impairs a person's behavior, judgment and ability to recognize reality or ability to meet the demands of normal life and includes mental conditions associated with the use or abuse of alcohol and drugs, but excludes mental retardation. It is also stated that mental illness shall be determined in accordance with nationally and internationally accepted medical standards.

7. Competence - The concept of 'competence' has been added in the Act, which is defined as ability to understand the information relevant to the decision and to retain, use or weigh the information as part of making decision and communicate his or her decision by any means. It is stated that all persons with mental illness are regarded as competent to make decisions except when they lack the ability as mentioned above.

8. Advance Directives - Every person has a right to make written statement specifying the way the person wishes to be or not to be cared for and treated for a mental illness and the individual or individuals he wants to be appointed as his nominated representative. The advance directive has to be signed by a medical practitioner certifying that the person is competent and aware of what he is doing. It may be revoked, amended or cancelled by the person who has made it. Medical professionals are duty bound to follow a valid advance directive. To over-rule a valid advance directive, an appeal can be made to the district panel of the MHRC. An advance directive which contains a refusal of all future medical treatment for mental illness has to be certified for validity by a district panel of the MHRC.

9. Nominated Representative - Any person with mental illness, who has attained the age of 18 years, has the right to appoint a nominated representative except when the person lacks the competence to make decisions. Such appointment shall be made in writing on plain paper and it will be countersigned by a medical practitioner certifying the competence of the person to do so. If no nominated representative has been appointed and no advance directive has been made, a relative described in section 2 (o) will be the nominated representative. If no family members are available, a care-giver (any person who normally resides with the person and/or predominantly responsible for providing care to that person) will be the nominated representative. If none of the above is available, nominated representative can be appointed by the district panel of the MHRC.

10. Rights of Persons with Mental IIlness - There is a separate chapter dealing with these rights. which includes right to access mental health care, right to community living, right to protection from cruel, inhuman and degrading treatment, right to equality and non-discrimination, right to confidentiality, right to access medical records, right to personal contacts and communication, right to legal aid and right to make complaints about deficiencies in provisions of services. The Act makes it obligatory for the government to make sufficient provision for a range of services required by persons of mental illness. It includes integration of mental health services into general health care services at all levels. The government has to ensure that no persons shall have to travel long distances to access mental health services and it will have to be made available in each district. The government shall have to submit annual report to the Parliament (or to state legislature in case of state government) regarding progress achieved in respect of access to mental health care. Persons with mental illness have a right of a safe and hygienic living environment, with adequate provision of food, facilities for recreation, privacy etc. They shall not be subjected to physical or sexual abuse or forced to compulsory work. There will be non-discrimination in respect of medical insurance and in respect of emergency medical services or any other health services. Persons with mental illness or their nominated representative shall have right to information and right to confidentiality and shall in general be given access to their medical records. But the psychiatrist may withhold information in case of likelihood of harm to the person with mental illness or to other persons and the person with mental illness shall have right to appeal to the District Panel of the MHRC in this respect. Free and informed consent is required from them in case research works. If they are unable to give free consent, permission will have to be obtained from the SMHA.

11. Duties of the Government - The government has been assigned duties to plan, promote and implement programmes for promotion of mental health and prevention of mental illnesses. Duty has been assigned to the government to take measures to create awareness about mental health illness and to reduce stigma associated with mental illness. The government 
is also obliged to take necessary measures to address the human resources requirement for mental health services as envisaged in the Act. 12. Mental Health Review Commission - In the previous draft a judicial body Mental Health Review Commission (MHRC) was proposed to be constituted by the State Government in each state. But in the third draft a three member MHRC is to be constituted by the Central Government. MHRC shall appoint and function through its District Panels which shall be based in the Districts. District panels shall receive guidance from the Commission on the interpretation of the Act and the procedures to be followed. MHRC and its district panels shall perform various functions prescribed in the Act. Appeal against the decision of the district panels shall lie to the High Court of the state.

13. State Mental Health Authorities - In the previous drafts as well as in MHA - 1987, Mental Health Authorities are to be established both at the Central and State levels. But in the third draft, only the State Mental Health Authority (SMHA) is proposed to be established by the state governments to perform various function under the act like registration \& supervision of mental health facilities in the state, registration mental health professionals in the state, training of all relevant persons about the provisions and implementation of the Act, advising the State Government on all matters relating to mental health and to ubmit an Annual Report to the State Legislature on progress of implementation of the various provisions of the Act.

14. Registration of Mental Health Facility - Licensing has been replaced with registration. In order to get registered, every mental health facility shall fulfill the minimum standards of facilities, minimum qualifications for the personnel, provisions for maintenance of records and reporting and any other conditions as may be prescribed. The registration is to be done by the State Mental Health Authority.

15.Inspecting officers and Visitors - Provisions of inspection at anytime by the inspecting officers, provisions of visitors for every mental health facility have been dropped in the draft. But, the State Mental Health Authority shall have right to cause an inspection of or inquiry in respect of any mental health facility, the result of which shall be communicated to the mental health facility. The Authority can issue any directions as it may deem fit and the mental health facility shall have to take action to the satisfaction of the Authority.
16.Admission Process - There are four types of admission, described as follows:

a. Independent admission - Any person who is not a minor can request for admission and can be admitted by the medical officer in-charge, if he is satisfied. If the independent patient requests for discharge, he will have to be discharged. But a mental health professional may prevent discharge of an independent patient seeking discharge for 24 hours, if the necessary conditions are met, to allow assessment by two mental health professionals necessary for supported admission under the Act.

b. Admission of a minor-A minor shall be admitted only in exceptional circumstances on application in writing of the nominated representative of the minor, on following the prescribed procedure. It is also specified that no irreversible treatment can be provided for the mental illness of a minor. They shall be accommodated separately from the adults. All admissions under this section will be informed to the district panel of MHRC within 72 hours. If admission continues beyond 30 days, it will again be informed to the district panel of MHRC. The District panel will make mandatory review within 7 days of all such admissions.

c. Supported admission up to 30 days - A person with mental illness may be admitted in a mental health facility, if two professionals, one psychiatrist and the other being a mental health professional or a registered medical practitioner, examine the person independently and both conclude that the person has a mental illness has recently threatened or attempted or is threatening or attempting to cause bodily harm to himself/herself and/or to another person and/or recently behaved or is behaving violently towards another person and/or has recently shown or is showing lack of competence to care for himself/herself. The admission under this section shall be limited to 30 days. All such admissions shall have to be informed to the district panel of the MHRC within 7 days, and in case of women, within 3 days.

d. Supported admission beyond 30 days - If the person is already admitted under section 45 and the criteria of admission as described above are still valid, the person will remain admitted if examined independently by two psychiatrists in the preceding 7 days and both certify that admission in the mental

Eastern J. Psychiatry Vol. 14, No. 1-2 
health facility is the least restrictive option possible. But all admissions under this section must be informed to the district panel of MHRC and will have to be approved by it within a period of 21 days from such admission. Admission under this section will be limited to 90 days. Further admission beyond 90 days can be renewed for 90 days at each instance upon application of the nominated representative and by following procedures as above.

17.Emergency Treatment - Under section 50, treatment can be initiated by any registered medical practitioner with the consent of nominated representative in certain specified emergency situations, at any health facility or in the community. But the treatment under this section will be limited to 72 hours and ECT and medical treatment not directly related to the emergency shall not be provided under this section.

18.Prohibited Treatments - ECT without use of muscle relaxants and anesthesia, ECT to minors and sterilization of persons with mental illness intended for treatment of mental illness is prohibited in the proposed draft. Psychosurgery may only be performed on approval of SMHA

19.Restrains and Seclusions - It is stated that person with mental illness cannot be chained in any manner whatsoever. Restrains and seclusions have to used when it is the only means available to prevent imminent and immediate harm to person concerned or to others and it has to be authorized by the psychiatrist in charge of the person's treatment at the mental health facility and may be used no longer than necessary

20.Duties of police officers and order in case of person with mental illness cruelly treated - Police officers have been assigned duties to take any wandering person with mental illness to the nearest public health facility within a period of 24 hours, where the medical officer in charge shall arrange for the assessment of the person at the nearest mental health facility and the needs of the person with mental illness will be addressed as the provisions of the Act. In case any person with mental illness is cruelly treated or not under proper care, a police officer or any private person may report the fact to a Magistrate, who may order for conveying the person to a mental health facility for assessment and treatment as per other provisions of the Act.
21. Effect of Act on other laws - The Act also provides that the provisions of this Act shall have effect notwithstanding anything inconsistent therewith contained in any other law for the time being in force and to the extent of such inconsistency that other law shall be deemed to have no effect (Sec 65).

\section{STANDS OF VARIOUS STAKEHOLDERS IN MHAAMENDMENT PROCESS}

Psychiatrists, allied mental health professionals, human rights activists groups and NGOs working in the field of mental health are the main stakeholder groups in the process of amendment to the MHA. The profession wants an Act which provides for least hassle in establishment of psychiatric hospitals or nursing home and exposed to minimum supervision by the government authorities. The profession also wants that the admission process should be smooth and their action of making admission of persons with mental illness should be exposed to as little scrutiny as possible. But the profession must concede a point that mentally ill persons are different than physically ill. Involuntary admission, which involves curtailment of personal liberty, does not take place in case of physically ill persons. Legal provisions are necessary for protecting basic human rights of persons with mental illness. Activists groups want stiff control on psychiatric institutions and practically a ban on involuntary admissions. But, they must realize that stringent provisions will be a great deterrent to establishment of services for persons with mental illness, which is already much scarce in our country. It must be realized that availability of services is necessary, otherwise persons with mental illness cannot attain highest attainable standard of health as per article 25 of the UNCRPD. Thus the stringent provision for establishment of psychiatric institutions will be self defeating in purpose.

Human right activists must realize that there are circumstances when the persons suffering from severe mental illness require to be treated for which they are not readily according their consent. There are circumstances when they have to be admitted, which prima facie appear to be involuntarily, as an indoor patient in a mental health facility for treatment. And all these are in their best interest. If the 'no force' principle is applied in absolute sense, they cannot be admitted, because they cannot be convinced for getting admitted for treatment. These patients suffer from 'delusions' which are beliefs not responsive to any amount of argument even though there is obvious evidence to the contrary. Persons with mental illness are basically different from persons with physical disability. Persons with pure physical disability have intact mental state and 
also intact capacity to make judgment about their interest. The 'no force' principle in exercise of their discretion of access to the support system is appropriate for them. For person with mental illness, the need to access the support system for exercise their legal capacity is by reasons of vitiation of their mental state itself. Therefore, the "noforce' cannot be applied in strict sense of term.

\section{SUGGESTIONS FOR IMPROVEMENT IN THE PROPOSED DRAFT}

The proposed draft of Mental Health Care Act has many positive features and it is modern in terminology and progressive in nature. The most salient feature of the proposed draft is it ensures institution of psychiatric health care delivery system and assigns obligation to the government for this purpose. Still, there are scopes for further improvement in it. Some suggestions in this respect are given as under.

- There should be some distinction between closed type of 'total care' mental health facility and the places where persons with mental illness stay with their families. The enforcement of stringent regulations in institutions where persons with mental illness stay with relatives is totally unnecessary. It would only be adding to the sorrow, pain and humiliation of the persons and their families, especially in the background of cruel stigma that already haunts all psychiatric illnesses (Antony, 2010). The proposed draft has an implicit provision in this respect by providing an exclusion criterion in the definition of mental health facility, which says, "...excludes a family residential place if a person with mental illness resides with his or her own family". But it is better to have an explicit differentiation with different set of rules for 'closed types of psychiatric institutions' and those with 'family ward' only.

- General Hospital Psychiatry Units (GHPU) is treated at par with other psychiatric institutions. This will prove to be a major dampener for establishment of psychiatry indoor units in general hospitals. In this way, psychiatry as a specialty will be cut off from the mainstream of medical profession. GHPU may contain only 'family wards' as suggested above, with a different set of rules and should be exempted from registration as mental health facility.

- State Mental Health Authority (SMHA) is overloaded with non-professional members. Psychiatrists should have better representation in it as psychiatrists are the persons with the best expertise so far as the matter of mental health is concerned. It is the psychiatrists world over who had historically led the movement to humanize mental health care and to reduce the stigma of the mental illness.

- Frequent reporting of supported admission will pose practical problems for mental health facilities and will increase paper and clerical works. This will pose practical problems for private mental health facilities and it may become a major dampener for establishment of private psychiatry units. In the long run, it will prove be detrimental to the interest of persons with mental illness themselves. Frequent reporting and review will also increase the workload of the district Panel of the MHRC, which is supposedly going to be overburdened with various works assigned to it.

- Prohibition of certain mode of treatment e.g. ECT without muscle relaxant and anaesthesia and ECT to minor is not proper. The choice of selection of treatment based upon scientific evidence should be the prerogative and discretion of the treating physician. There should not any legislative ban on any mode of treatment which is based on scientific evidence.

- There should be some provision for involuntary treatment in OPD services. Involuntary treatment may be required in the OPD and also in private consultation practice of psychiatry. For example, if a violent patient is required to be administered some injection in OPD practice, there is no provision in the existing Act to permit it. Therefore, for administering any involuntary treatment, the person with mental illness has to be admitted in mental health facility. With advancement of psychopharmacology, even severe psychotic cases can be managed at the patient's home itself with the help of their family members. Therefore, some legislative provision in this respect would definitely be appropriate.

\section{CONCLUSION:}

Mental Health Act is the Act meant for the persons with mental illness and not for the profession or the activist groups. This fact must be kept in mind by everyone in the process of drafting the Act. Therefore, it is imperative that it should be directed towards betterment of the conditions and protection of the rights of persons with mental illness. Protection of human rights of persons with mental illness is quite necessary, but it should not be so overstretched that their welfare and proper care itself is

Eastern J. Psychiatry Vol. 14, No. 1-2 
endangered. It is in the interest of everyone if in the new Act, the emphasis is on ensuring easy availability of psychiatric treatment to all, finding ways to promote opening of more and more psychiatric inpatient facility, providing for better care of wandering persons with mental illness and protecting and promoting rights of persons with mental illness.

\section{Reference:}

1. Agrawal, AK, The Mental Health and the Law, Indian Journal of Psychiatry; 1992; 34: 65-67

2. Antony, JT, A Decade with the Mental Health Act, Indian Journal of Psychiatry, 2000;42(4): 347-355

3. Antony, JT, On Drafting a New Medical Act, Indian Journal of Psychiatry, 2010; 52(1): 9-12

4. Das, SK, The Mental Health Act - 1987 and Current Issues; Presidential Address delivered at IPS - EZ Conference at Patna, 2002

5. Dhanda, A, Status Paper on Rights of Persons living with Mental Illness in the light of the UNCRPD, in Harmonizing Laws with UNCRPD, Report prepared by the Centre for Disability Studies, NALSAR University of Law, Hyderabad

6. Dutta, AB, Medico-legal Problems of Psychiatrists in Private Practice, Journal of Clinical Psychiatry, 1995; vol. 1, no. I 7. Dutta, AB, (1987) - Mental Health Act, 1987: A Critical Approach, Proceedings of Workshop on Ethics in Psychiatry, 117-147, KG Medical College, Lucknow

8. Dutta, AB, (2001) The Long March of Mental Health Legislation in Independent India; Dr. L. P. Shah Oration delivered at IPS-WZ Conference at Goa, 2001, published by Goa Psychiatry Society

9. Government of India - The Mental Health Act- 1987, published by Delhi Law House in 2002
10. Kala, A, A Call for Amendments in the Licensing Provisions of Mental Health Act - 1987, J. Mental Health Hum Behav, 1997; 2:101-102

11. Kala, A, Why We Should Opt For a New Mental Health Act, And Not Tinker with the Old One, Indian Journal of Psychiatry, 2004, 46(2), 96-98

12. Malik, SC, Mental Health Programme and Legislation : Some Observation and Experiences, Indian Journal of Psychiatry, 2004, 46(1), 15-24

13. Narayan, CL, Jaiswal, $R$ \& Shikha, D, - Towards a New Mental Health Act, Eastern Journal of Psychiatry, 2010; 13(1\&2):95-100

14. Pathare, S and Sagade, J. (2010) - Working Papers on Amendments to MHA-1987 prepared on behalf of Ministry of Health, GOI, Centre for Mental Health Law and Policy, Indian Law Society, Pune, Draft dated 28-02-10, 23-05-10 \& 06-12-10

15. Sarkar, J, A New Mental Health Act for India: An Ethics based Approach, Indian Journal of Psychiatry, 2004; 46(2),:104-114

16. World Health Organization (2001) - Presence of Mental Health Policies and Legislations, Mental Health: New Understanding, New Hope, World Health Report, 2001, WHO Press, Geneva

Address: 1) Dr. C. L.Narayan

MBBS, MD, FIPS, FIAPP

Consultant Psychiatrist, Gaya, Bihar, drclnarayan@gmail.com

3) Dr. Rajiv Jaiswal, MBBS

Junior Resident

Department of Psychiatry 'Deepayan', Tilha, Kali Bari, Safdarjung Hospital, New Delhi, drjaiswalrajeev@gmail.com 